\title{
Dual Band MIMO Antenna Composed of Two Low Profile Unbalanced Fed Inverted L Antennas for Wireless Communications
}

\author{
Erfan Rohadi', ${ }^{1}$, Mitsuo Taguchi1 \\ ${ }^{1}$ Graduate School of Engineering, Nagasaki University, Nagasaki, Japan \\ ${ }^{2}$ The State Polytechnic of Malang, Malang, Indonesia \\ Email: bb52211281@cc.nagasaki-u.ac.jp, erfanr@polinema.ac.id, mtaguchi@nagasaki-u.ac.jp
}

Received 18 April 2014; revised 21 May 2014; accepted 10 June 2014

Copyright (C) 2014 by authors and Scientific Research Publishing Inc.

This work is licensed under the Creative Commons Attribution International License (CC BY). http://creativecommons.org/licenses/by/4.0/

(c) (i) Open Access

\section{Abstract}

A low profile dual-band multiple-input-multiple-output (MIMO) antenna system is proposed. The proposed MIMO antenna consists of two low profile unbalanced fed inverted $L$ antennas with parasitic elements to resonate at $2.45 \mathrm{GHz}$ and $5 \mathrm{GHz}$. The structure is uncomplicated by locating two ultra low profile inverted $L$ antennas on the finite conducting plane. The proposed MIMO antenna is numerically and experimentally analyzed. When the size of conducting plane is $55 \mathrm{~mm}$ by 55 $\mathrm{mm}$ and the height of antenna is $9 \mathrm{~mm}$, the directive gain of $4.11 \mathrm{dBi}$ and the $S_{11}$ bandwidth of $5.71 \%$ are achieved for lower frequency of $2.45 \mathrm{GHz}$. At the upper frequency of $5 \mathrm{GHz}$, the directive gain of $8.22 \mathrm{dBi}$ and the $S_{11}$ bandwidth of $6 \%$ are obtained. The proposed antenna has good diversity gain, shown by the correlation coefficient becomes less than 0.005 at the frequency of 2.45 GHz and $5 \mathrm{GHz}$ band when the distance between inverted L elements is $41 \mathrm{~mm}$. A good agreement between calculated and measured results is obtained. The results show that the weak mutual coupling of the proposed antenna and this feature enables it to cover the required bandwidths for WLAN operation at the $2.4 \mathrm{GHz}$ band and $5 \mathrm{GHz}$ band.

\section{Keywords}

Dual Band MIMO, Inverted L Antenna, ILA, Low Profile Antenna, Parasitic Element, Correlation Coefficients, ISM, WCS

\section{Introduction}

The dual band antennas have been investigated with the development of wireless communication systems in re-

How to cite this paper: Rohadi, E. and Taguchi, M. (2014) Dual Band MIMO Antenna Composed of Two Low Profile Unbalanced Fed Inverted L Antennas for Wireless Communications. Wireless Engineering and Technology, 5, 54-61. 
cent years [1]-[8]. Most of these dual or multiple band antennas have an omnidirectional radiation pattern. In some applications such as wireless base station or access point, the unidirectional radiation pattern is needed. In order to realize the unidirectional radiation pattern, the antenna size becomes larger [4] [6] [8]. A higher order mode maybe excited in such antenna and large ripples may exist in the radiation pattern at the upper frequency bands [4]-[6]. The interference and the antenna gain reduction may occur due to the large ripple for base station or access point applications. Therefore the compact dual band antenna with unidirectional radiation pattern is desired. The dual or multiple band MIMO antennas are widely used for wireless communication because they become as an effective solution to enhance the channel capacity [9] [10]. One of authors has proposed the dual band antenna composed of the unbalanced fed inverted $\mathrm{L}$ antenna for $1.4 \mathrm{GHz}$ and $2.2 \mathrm{GHz}$ bands [11]. In [11], the parasitic element was located above an unbalanced fed inverted $L$ antenna for higher band excitation. This antenna is promising as the candidate of the dual band antenna because it provides two distinct resonant modes for achieving dual-band operation. Furthermore, the authors have studied the advantages of inverted L antennas for wireless communication systems [12] [13], and proposed the simple design and low cost material antenna for single band MIMO antenna systems [14] [15].

In this paper, a dual band MIMO antenna composed of two parallel identical ultra low profile inverted L antennas located on square conducting plane. The proposed antenna has a simple design and works at frequency bands of $2.45 \mathrm{GHz}$ and $5 \mathrm{GHz}$. In order to satisfy the MIMO antenna system requirements, the proposed antenna is investigated on mutual coupling between two inverted $\mathrm{L}$ elements and diversity gain through correlation coefficient value [16]-[19]. The electromagnetic simulator WILP-D based on the method of moments is used for numerical analysis for the reason of shorter computation time compared with other simulation methods [20]. Then its results are validated with the measurement.

\section{Antenna Structure}

Figure 1 shows the proposed dual band MIMO antenna. The proposed structure is configured by two low profile inverted $L$ antennas located on finite conducting plate with dimension $55 \mathrm{~mm}$ by $55 \mathrm{~mm}\left(0.45 \lambda_{2.45}\right.$ by 0.45 $\lambda_{2.45}$ ). $\lambda_{2.45}$ is the wavelength at the frequency of $2.45 \mathrm{GHz}$. The parasitic element is placed above the horizontal element of low profile inverted $L$ antenna. The feed points are located at the distance $L_{1}$ from the bend of horizontal elements of the inverted $L$ antennas. Both the lengths of $L_{1}$ and $L$ are adjusted to obtain the $50 \mathrm{Ohm} \mathrm{im-}$ pedance matching. In the calculation, the height of inverted $L$ antenna $h_{1}$ is set as $5 \mathrm{~mm}$ or $6 \mathrm{~mm}$. The length of parasitic elements $L_{p}$ is determined so that the upper resonant frequency becomes to be $5 \mathrm{GHz}$. In the previous study in [12], the optimum distance between two inverted $L$ antennas was $41 \mathrm{~mm}$ in the case of the conducting plane was $55 \mathrm{~mm}$ by $55 \mathrm{~mm}$. Therefore the distance between inverted $\mathrm{L}$ antennas $d$ is set to be $41 \mathrm{~mm}$. The inverted $\mathrm{L}$ antenna is composed of the semi rigid coaxial cables with the radius of inner and outer conductors are $0.255 \mathrm{~mm}$ and $1.095 \mathrm{~mm}$, respectively. The radius of parasitic elements is $1.095 \mathrm{~mm}$. The distance between the vertical element of inverted $\mathrm{L}$ antennas and the edge on backside pym is set as $10 \mathrm{~mm}$. The distance between the vertical element of inverted $\mathrm{L}$ antennas and the edge on front side pyp is set as $45 \mathrm{~mm}$. The distances between vertical element of inverted $\mathrm{L}$ antennas and outer edge on right and left side $p x p$ are fixed as $7 \mathrm{~mm}$.

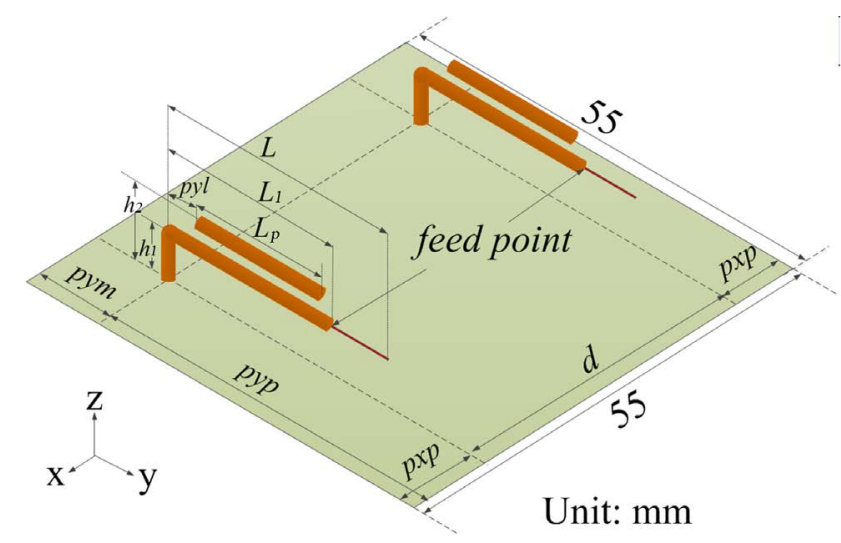

\begin{tabular}{ccc}
\hline Antenna parameters & \multicolumn{2}{c}{ Unit:mm } \\
\hline$L$ & 28.9 & 29.9 \\
$L_{1}$ & 14.4 & 16.8 \\
$L_{p}$ & 27.1 & 27.3 \\
$h_{1}$ & 6 & 5 \\
$h_{2}$ & 9 & 8 \\
$p y l$ & 4.6 & 4.0 \\
inner radius of wire & \multicolumn{2}{c}{0.255} \\
outer radius of wire & \multicolumn{2}{c}{1.095} \\
conducting plane dimension & $55 \times 55$ \\
$d$ & \multicolumn{2}{c}{41} \\
pxp & \multicolumn{2}{c}{7} \\
pym & \multicolumn{2}{c}{10} \\
pyp & 45
\end{tabular}

Figure 1. The structure of proposed MIMO antenna. 


\section{Results and Discussion}

Figure 2 show the calculated scattering parameters of proposed MIMO antenna. The $\mathrm{S}_{11}$ bandwidth less than $-10 \mathrm{~dB}$ of the proposed antenna are $5.71 \%(2.38-2.52 \mathrm{GHz})$ for lower frequency band and $6 \%(4.87-5.17$ $\mathrm{GHz}$ ) for higher frequency band. The mutual coupling between two ports is less than $-21 \mathrm{~dB}$ in the lower band and less than $-23 \mathrm{~dB}$ in the higher one.

Figure 3(a) and Figure 3(b) show the calculated current distributions at lower frequency of $2.45 \mathrm{GHz}$ and higher frequency of $5 \mathrm{GHz}$. The height of inverted L antenna and parasitic element are $h_{1}=6 \mathrm{~mm}$ and $h_{2}=9$ mm, respectively. Figure 4(a) and Figure 4(b) show the calculated current distributions when $h_{1}=5 \mathrm{~mm}$ and $h_{2}$ $=8 \mathrm{~mm}$. A surface current on the conducting plane between two inverted L antennas is small. This means that the proposed structure achieves a good isolation. When the height of inverted $\mathrm{L}$ antenna is $5 \mathrm{~mm}$, a large surface current flows on the conducting plane under the inverted L antenna. Due to the strong mutual coupling between inverted $\mathrm{L}$ antenna and the conducting plane, the frequency bandwidth becomes slightly narrow.

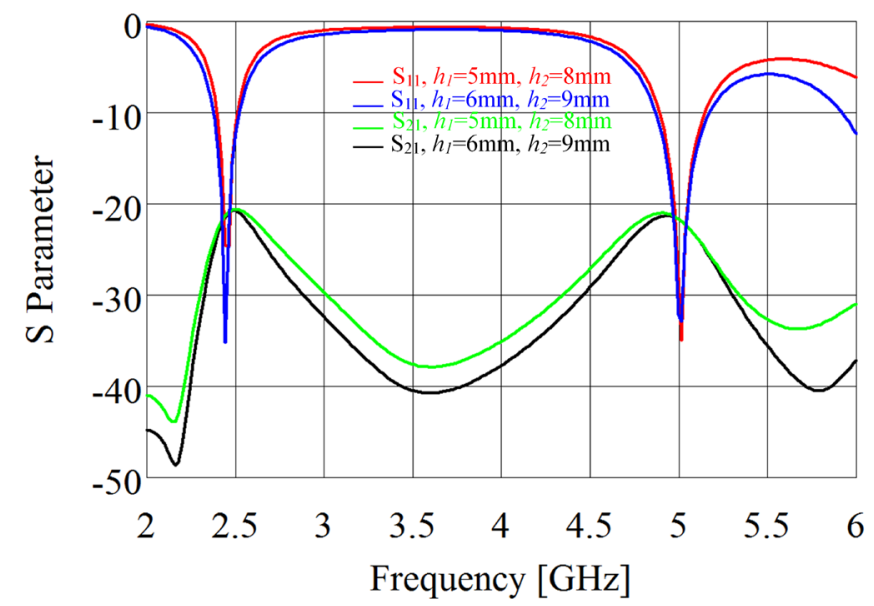

Figure 2. Calculated scattering parameter of proposed antenna. pyp $=45 \mathrm{~mm}$, $x p=7 \mathrm{~mm}$, pym $=10 \mathrm{~mm}, d=41 \mathrm{~mm}$.

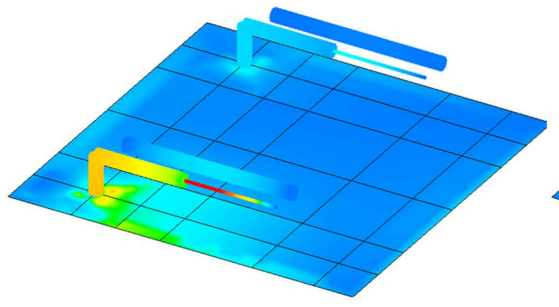

(a)

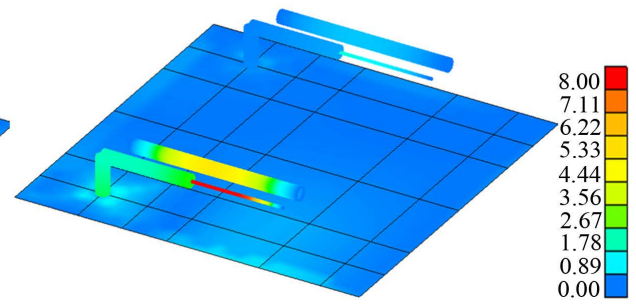

(b)

Figure 3. Current distributions of proposed antenna. $h_{1}=6 \mathrm{~mm}, h_{2}=9 \mathrm{~mm}$, pyp $=45 \mathrm{~mm}$, pxp $=7 \mathrm{~mm}$, pym $=10 \mathrm{~mm}, d=41 \mathrm{~mm}$. (a) $2.45 \mathrm{GHz}$; (b) $5 \mathrm{GHz}$.

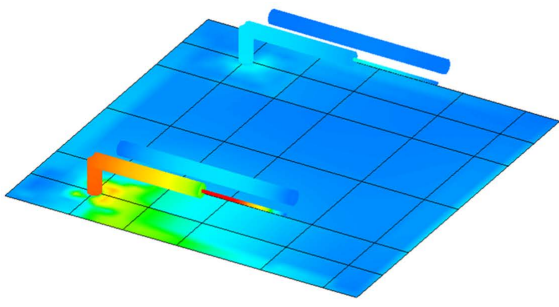

(a)

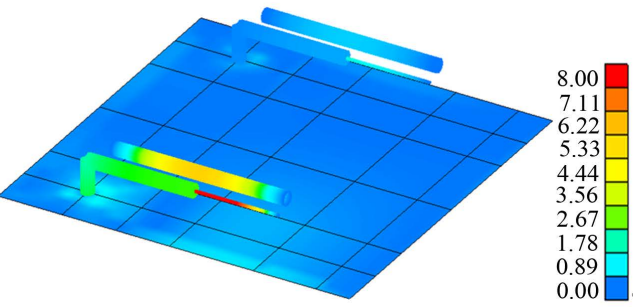

(b)

Figure 4. The calculated current distributions of proposed antenna. $h_{1}=5 \mathrm{~mm}, h_{2}=8 \mathrm{~mm}$, pyp $=$ $45 \mathrm{~mm}$, pxp $=7 \mathrm{~mm}$, pym $=10 \mathrm{~mm}, d=41 \mathrm{~mm}$. (a) $2.45 \mathrm{GHz}$; (b) $5 \mathrm{GHz}$. 
Figure 5 show the comparison of calculated and measured scattering parameters of proposed MIMO antenna when the height of inverted L antenna and parasitic elements are $h_{1}=6 \mathrm{~mm}$ and $h_{2}=9 \mathrm{~mm}$, respectively. The scattering parameters are measured by the $6 \mathrm{GHz}$ board network analyzer R3760 by Advantest. The measured scattering parameters agree well with the calculated ones.

Figure 6 shows the directive gain of proposed MIMO antenna in the $z$ direction. In both of cases of antenna height, the almost the same directive gain $4.11 \mathrm{dBi}$ is obtained at $2.45 \mathrm{GHz}$. At $5 \mathrm{GHz}$, the current on the parasitic element is strongly excited. Since the equivalent size of antenna becomes large, the directive gain more than $8.11 \mathrm{dBi}$ is obtained at this frequency.

The MIMO antenna system correlation factor will be significantly degraded with high coupling levels. It can be calculated from the scattering parameters in isotropic/uniform signal propagation [21]. The correlation coefficient $\rho_{e}$ is important to achieve the required diversity gain of the MIMO antenna systems. When $\rho_{e}$ becomes lower, the higher diversity gain is obtained. The value of $\rho_{e}$ can be calculated by using [22];

$$
\rho_{e}=\frac{\left|S_{11} * S_{12}+S_{21} * S_{22}\right|^{2}}{\left(1-\left(\left|S_{11}\right|^{2}+\left|S_{21}\right|^{2}\right)\right)\left(1-\left(\left|S_{22}\right|^{2}+\left|S_{12}\right|^{2}\right)\right)}
$$

Figure 7 show the calculated correlation coefficients in two cases of antenna height. It is evident that the proposed antenna with enhanced isolation satisfies the MIMO requirements for spatial diversity with the value of $\rho_{e}$ are less than 0.005 at both of lower and upper frequency bands. Figure 8 shows the calculated and meas-

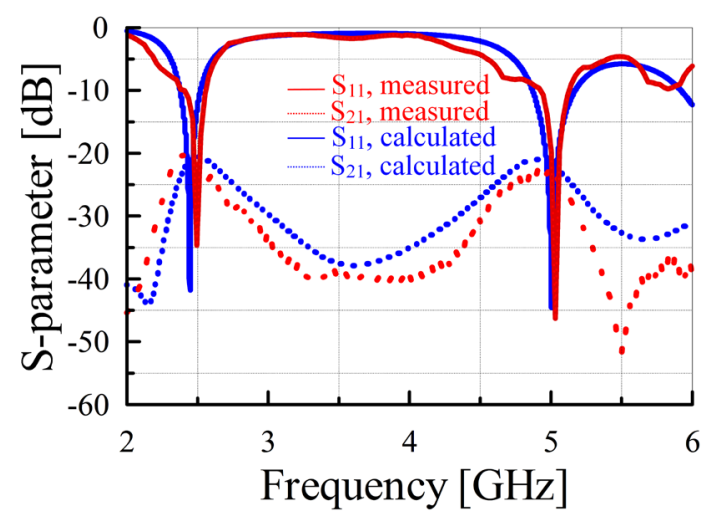

Figure 5. Calculated and measured scattering parameter. $h_{1}=6 \mathrm{~mm}, h_{2}=9 \mathrm{~mm}$, pyp $=45 \mathrm{~mm}, p x p=7 \mathrm{~mm}$, pym $=10 \mathrm{~mm}, d=41 \mathrm{~mm}$.

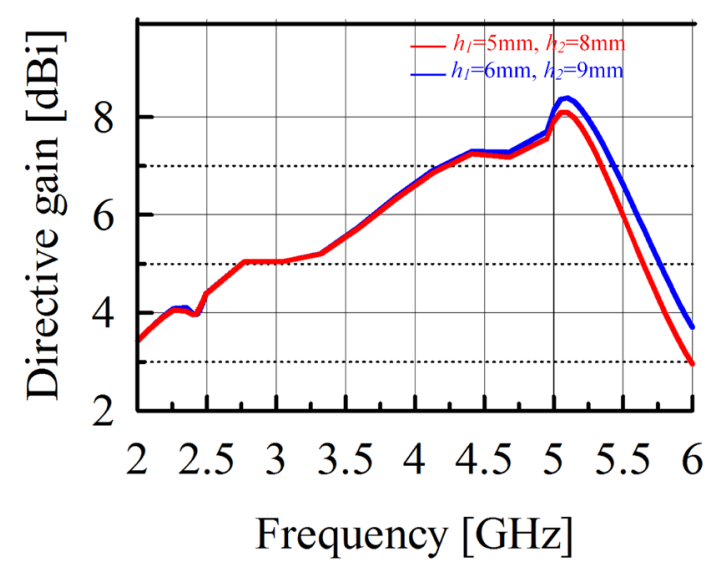

Figure 6. The directive gain of the proposed antenna in $z$ direction. $p y p=45 \mathrm{~mm}, p x p=7 \mathrm{~mm}$, pym $=10 \mathrm{~mm}, d$ $=41 \mathrm{~mm}$. 


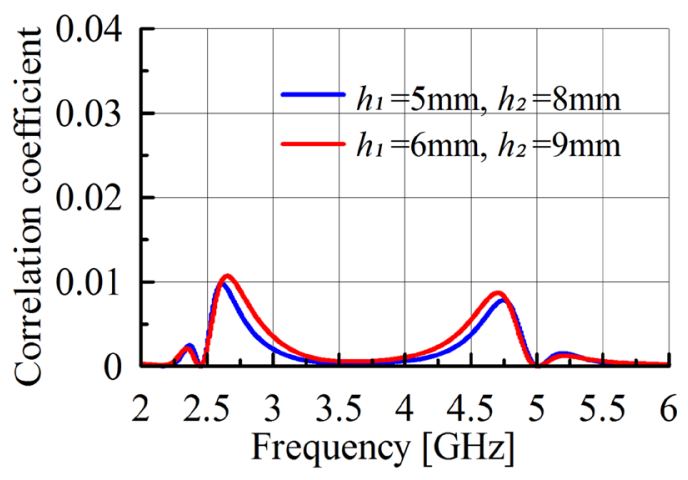

Figure 7. Correlation coefficient. $p y p=45 \mathrm{~mm}, p x p=$ $7 \mathrm{~mm}$, pym $=10 \mathrm{~mm}, d=41 \mathrm{~mm}$.

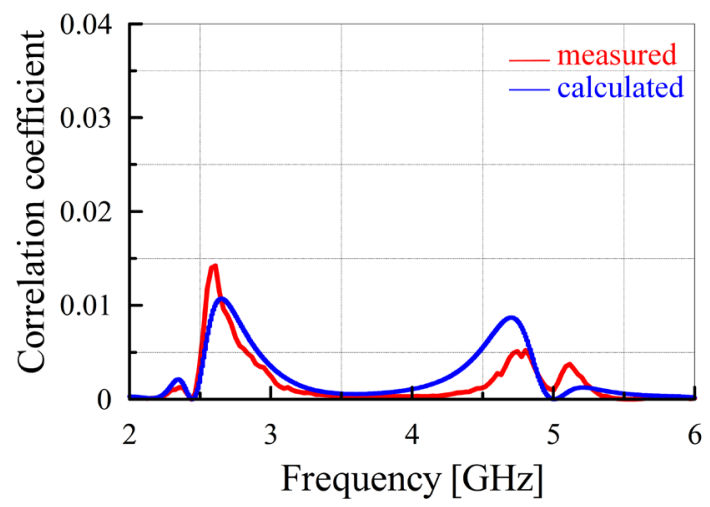

Figure 8. Correlation coefficient. $h_{1}=6 \mathrm{~mm}, h_{2}=9$ $\mathrm{mm}$, pyp $=45 \mathrm{~mm}$, pxp $=7 \mathrm{~mm}$, pym $=10 \mathrm{~mm}, d=41$ $\mathrm{mm}$.

ured correlation coefficient of the proposed MIMO antenna when the height of inverted antenna and the height of antenna elements are $6 \mathrm{~mm}$ and $9 \mathrm{~mm}$, respectively. A good agreement between calculated and measured results is obtained.

Figure 9 show the calculated electric field radiation pattern in $x y$-plane, $x z$-plane and $y z$-plane at $2.45 \mathrm{GHz}$ and $5 \mathrm{GHz}$ when the height of inverted $\mathrm{L}$ antenna is $h_{1}=6 \mathrm{~mm}$ and height of parasitic element is $h_{2}=9 \mathrm{~mm}$, respectively. When the height of inverted of inverted $\mathrm{L}$ antenna is reduced to $5 \mathrm{~mm}$, the calculated electric field radiation pattern are shown at Figure 10.

As a result, the radiation patterns of the proposed antenna tends to cover complementary space region, which can provide pattern diversity to overcome the multipath fading problem and enhance the system performance.

Figure 11 shows the calculated near field distribution of the proposed antenna in $x z$-plane including the feed point in the case of $h_{1}=6 \mathrm{~mm}$ and $h_{2}=9 \mathrm{~mm}$. The weak mutual coupling between two inverted L antennas is archived. It clearly illustrates that the spatial coupling is dominant at operation frequency bands since the small current are flowing on the conducting plane between two inverted $\mathrm{L}$ antennas.

\section{Conclusion}

In this paper, a simple design and fabrication of dual band MIMO antenna composed of two ultra low profile inverted L antenna has been presented. The proposed antenna satisfies the MIMO system requirements with correlation coefficient less than 0.005 at both frequency bands. When the antenna size is $55 \mathrm{~mm}$ by $55 \mathrm{~mm}$ by 9 $\mathrm{mm}$, the $\mathrm{S}_{11}$ bandwidth of $5.71 \%(140 \mathrm{MHz})$ at lower band of $2.45 \mathrm{GHz}$ and $6 \%$ (300 MHz) at upper band of 5 $\mathrm{GHz}$ are obtained. The directive gains are $4.11 \mathrm{dBi}$ at $2.45 \mathrm{GHz}$ and $8.22 \mathrm{dBi}$ at $5 \mathrm{GHz}$. The good agreement of calculated and measured scattering parameters and the correlation coefficients are obtained. The presented design is suitable for MIMO communication applications. 


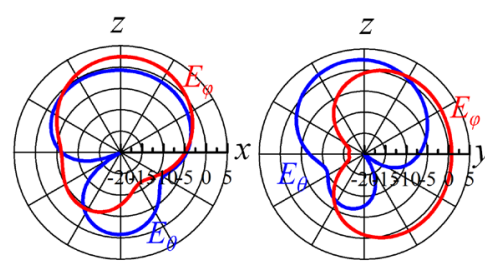

(a)

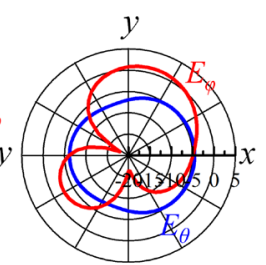

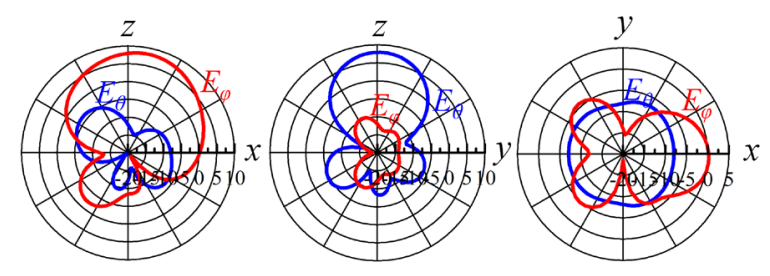

(b)

Figure 9. Electric field radiation pattern. $h_{1}=6 \mathrm{~mm}, h_{2}=9 \mathrm{~mm}$, pyp $=45 \mathrm{~mm}, p x p=7 \mathrm{~mm}$, pym $=10 \mathrm{~mm}, d=41 \mathrm{~mm}$. (a) $2.45 \mathrm{GHz}$; (b) $5 \mathrm{GHz}$.
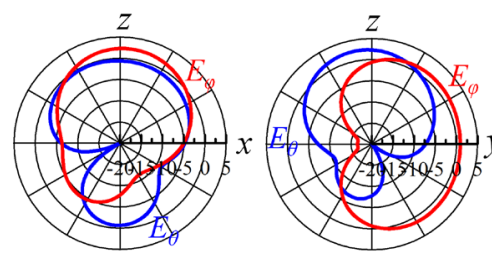

(a)

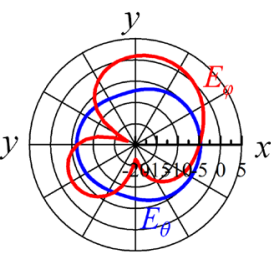

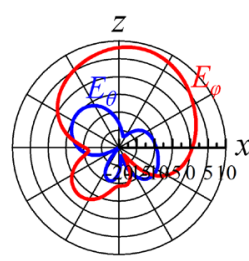

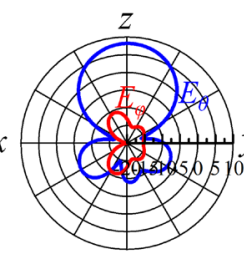

(b)

Figure 10. Electric field radiation pattern. $h_{1}=5 \mathrm{~mm}, h_{2}=8 \mathrm{~mm}$, pyp $=45 \mathrm{~mm}, p x p=7 \mathrm{~mm}, p y m=10 \mathrm{~mm}, d=41 \mathrm{~mm}$. (a) $2.45 \mathrm{GHz}$; (b) $5 \mathrm{GHz}$.
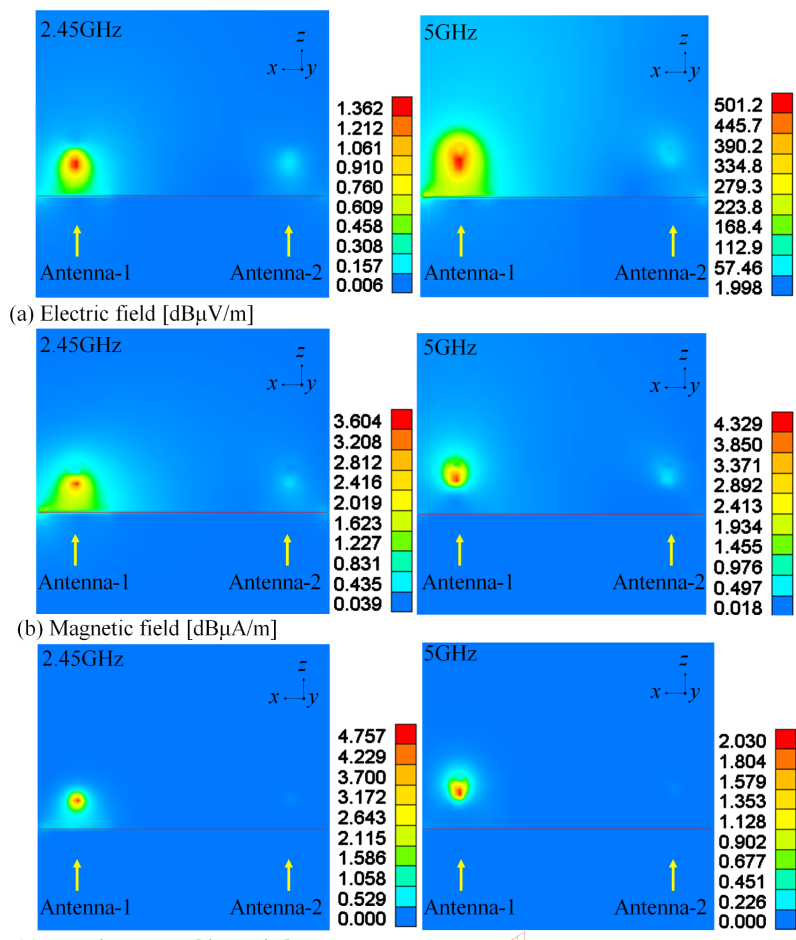

(c) Poynting vector $[\mathrm{dB} \mu \mathrm{W} / \mathrm{m}]$
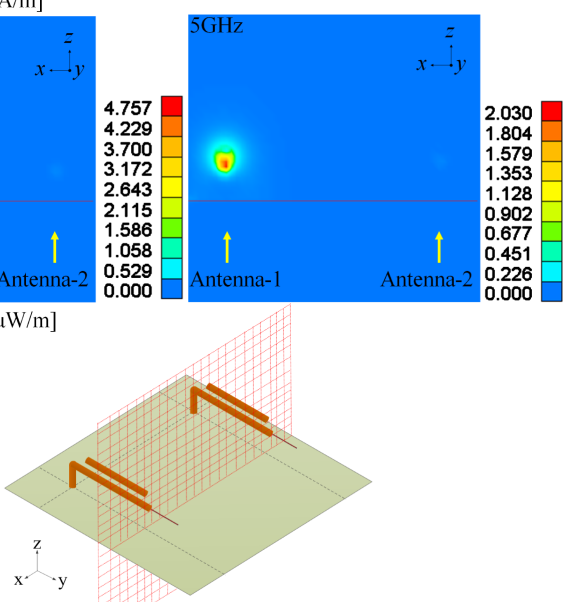

Figure 11. The near field distribution at $2.45 \mathrm{GHz}$ and $5 \mathrm{GHz}\left(h_{1}=6 \mathrm{~mm}, h_{2}=9 \mathrm{~mm}, \mathrm{~d}=41\right.$ $\mathrm{mm}$, pxp $=7 \mathrm{~mm}$, pym $=10 \mathrm{~mm}$, pyp $\left.=45 \mathrm{~mm}, L=28.9 \mathrm{~mm}, L_{1}=14.2 \mathrm{~mm}, L_{p}=27.1 \mathrm{~mm}\right)$. 


\section{Acknowledgements}

ErfanRohadi would like to thank to the General of Higher Education, Ministry Education and Culture of Republic Indonesia for providing the scholarship of the doctoral course program.

\section{References}

[1] Kuo, Y.L. and Wong, K.L. (2003) Printed Double-T Monopole Antenna for 2.4/5.2 GHz Dual-Band WLAN Operations. IEEE Transactions on Antennas and Propagation, 51, 2187-2192. http://dx.doi.org/10.1109/TAP.2003.816391

[2] Ding, Y., Du, Z., Gong, K. and Feng, Z. (2007) A Novel Dual-Band Printed Diversity Antenna for Mobile Terminal. IEEE Transactions on Antennas and Propagation, 55, 2088-2096. http://dx.doi.org/10.1109/TAP.2007.900249

[3] Jan, J.Y. and Tseng, L.C. (2004) Small Planar Monopole Antenna with a Shorted Parasitic Inverted-L Wire for Wireless Communications in the 2.4, 5.2, and 5.8-GHz Bands. IEEE Transactions on Antennas and Propagation, 52, 19031905. http://dx.doi.org/10.1109/TAP.2004.831370

[4] Wong, K.L., Chou, L.C. and Su, C.M. (2005) Dual-Band Flate-Plate Antenna with a Shorted Parasitic Element for Laptop Applications. IEEE Transactions on Antennas and Propagation, 53, 539-544. http://dx.doi.org/10.1109/TAP.2004.838754

[5] Chen, S.B., Jiao, Y.C., Wang, W. and Zhang, F.S. (2006) Modified T-Shaped Planar Monopole Antennas for Multiband Operation. IEEE Transactions on Microwave Theory and Techniques, 54, 3267-3270. http://dx.doi.org/10.1109/TMTT.2006.877811

[6] Chou, L.C. and Wong, K.L. (2007) Uni-Planar Dual-Band Monopole Antenna for 2.4/5 GHz WLAN Operation in the Laptop Computer. IEEE Transactions on Antennas and Propagation, 55, 3739-3741. http://dx.doi.org/10.1109/TAP.2007.910501

[7] Li, R.L., Pan, B., Laskar, J. and Tentzeris, M.M. (2008) A Novel Low-Profile Broadband Dual-Frequency Planar Antenna for Wireless Handsets. IEEE Transactions on Antennas and Propagation, 56, 1155-1162. http://dx.doi.org/10.1109/TAP.2008.919171

[8] Li, R., Wu, T. and Tentzeris, M. (2008) A Dual-Band Unidirectional Coplanar Antenna for 2.4 - 5-GHz Wireless Application. Proceedings of the Asia-Pacific Microwave Conference, December 2008, 1-4. http://dx.doi.org/10.1109/APMC.2008.4958537

[9] Yu, X.H., Wang, L., Wang, H.G., Wu, X.D. and Shang, Y.H. (2012) A Novel Multiport Matching Method for Maximum Capacity of an Indoor MIMO System. Progress in Electromagnetics Research, 130, 67-34. http://dx.doi.org/10.2528/PIER12040603

[10] Zhang, J., Yang, J.O., Zhang, K.Z. and Yang, F. (2012) A Novel Dual-Band MIMO Antenna with Lower Correlation Coefficient. International Journal of Antennas and Propagation, 2012, Article ID: 512975. http://dx.doi.org/10.1155/2012/512975

[11] Sato, S. and Taguchi, M. (2012) Dual Band Ultra Low Profile Inverted L Antenna. Proceedings of International Symposiumon Antennas and Propagat, 29 October-2 November, 1417-1420.

[12] Yamashita, T. and Taguchi, M. (2009) Ultra Low Profile Inverted L Antenna on a Finite Conducting Plane. Proceedings of International Symposiumon Antennas and Propagat, Bangkok, 20-23 October, 361-364.

[13] Rohadi, E. and Taguchi, M. (2012) Ultra Low Profile Antenna for 2.45 GHz Wireless Communications. Proceedings of IEEE International Conferece on Communication and Satellite (Comnetsat), 103-107.

[14] Rohadi, E. and Taguchi, M. (2013) Two Element Ultra Low Profile Inverted L Antennas on Finite Conducting Plate for MIMO Applications. Proceedings of IEEE International Conference on Advanced Technologies for Communications (ATC), Ho Chi Minh City, 16-18 October 2013, 74-77.

[15] Rohadi, E. and Taguchi, M. (2014) Two Low Profile Unbalanced Fed Inverted L Elements on Square Conducting Plane for MIMO Application. Wireless Engineering and Technology, 5, 34-43. http://dx.doi.org/10.4236/wet.2014.52005

[16] Costa, J.R., Lima, E.B., Medeiros, C.R. and Fernandes, C.A. (2011) Evaluation of a New Wideband Slot Array for MIMO Performance Enhancement in Indoor WLANs. IEEE Transactions on Antennas and Propagation, 59, 12001206. http://dx.doi.org/10.1109/TAP.2011.2109685

[17] Cui, S., Gong, S.X., Liu, Y. and Guan, Y. (2011) Compact and Low Coupled Monopole Antennas for MIMO Systems Applications. Journal of Electromagnetic Waves and Applications, 25, 703-712. http://dx.doi.org/10.1163/156939311794827221

[18] Abouda, A.A. and Hagman, S.G. (2006) Effect on Mutual Coupling Capacity on MIMO Wireless Channels in High SNR Scenario. Progress in Electromagnetic, 65, 27-40. http://dx.doi.org/10.2528/PIER06072803 
[19] Votis, C., Tati, G. and Kostarakis, P. (2010) Envelope Correlation Parameter Measurements in a MIMO Antenna Array Conficguration. International Journal of Computer Science and Communication Networks, 3, 350-354.

[20] WIPL-D d.o.o. (2013) WIPL-D Pro v11.0. http://www.wipl-d.com/

[21] Paul, H. (2005) The Significance of Radiation Efficiencies When Using S-Parameter to Calculate the Received Signal Correlation from Two Antennas. IEEE Antennas and Wireless Propagation Letters, 4, 97-99. http://dx.doi.org/10.1109/LAWP.2005.845913

[22] Thaysen, J. and Jakobsen, K.B. (2006) Envelope Correlation in (N,N) MIMO Antenna Array from Scattering Parameters. Microwave and Optical Technology Letters, 48, 832-834. http://dx.doi.org/10.1002/mop.21490 
Scientific Research Publishing (SCIRP) is one of the largest Open Access journal publishers. It is currently publishing more than 200 open access, online, peer-reviewed journals covering a wide range of academic disciplines. SCIRP serves the worldwide academic communities and contributes to the progress and application of science with its publication.

Other selected journals from SCIRP are listed as below. Submit your manuscript to us via either submit@scirp.org or Online Submission Portal.
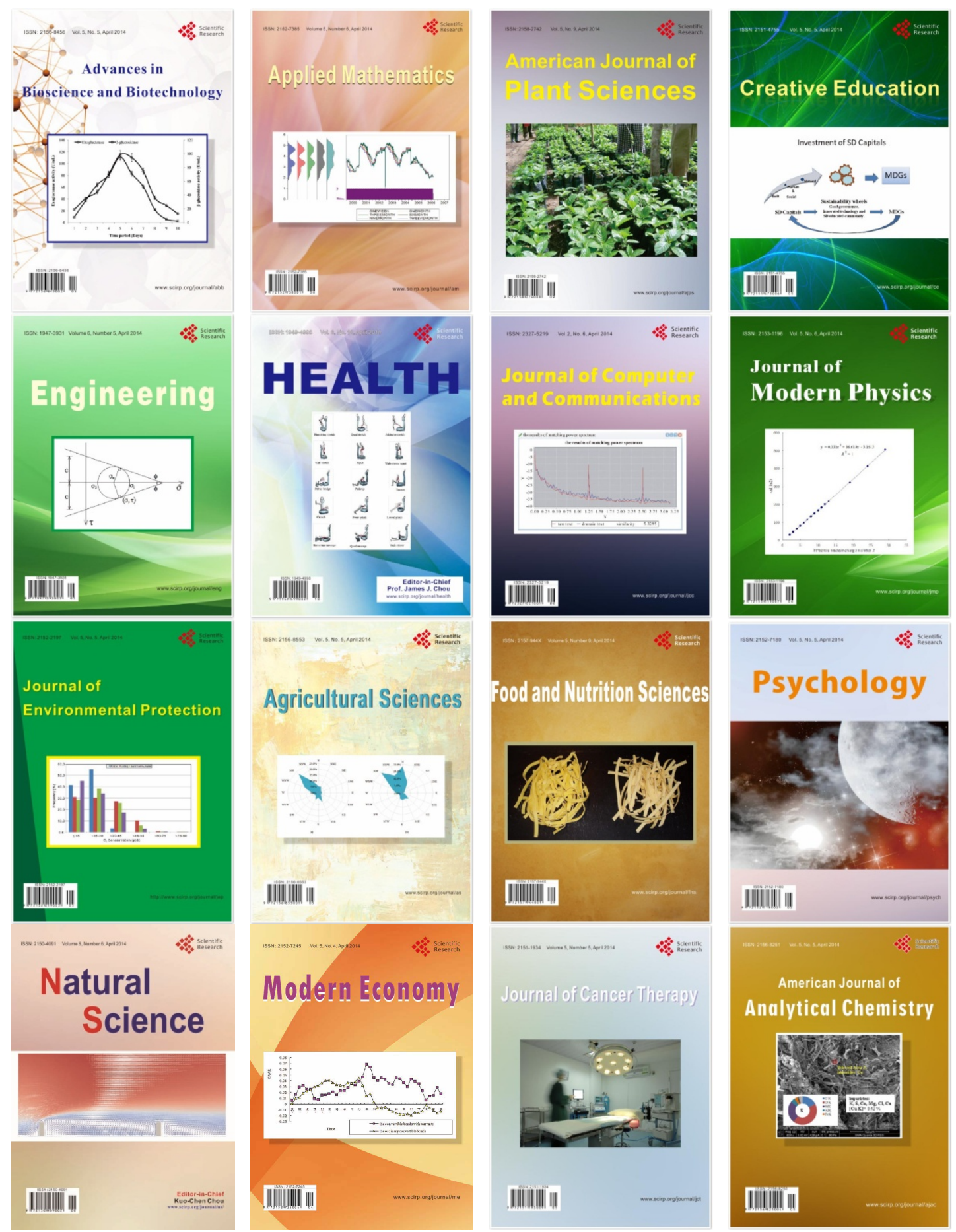